\title{
Is Smartphone Addiction Associated with a Younger Age at First Use in University Students?
}

\author{
Doris Jaalouk $^{1} \&$ Jocelyne Boumosleh ${ }^{1}$ \\ ${ }^{1}$ Department of Nursing and Health Sciences, Notre Dame University-Louaize, Zouk Mosbeh, Lebanon \\ Correspondence: Doris Jaalouk, Faculty of Nursing \& Health Sciences, Notre Dame University-Louaize, P.O.Box: \\ 72, Zouk Mikael, Zouk Mosbeh, Lebanon. Tel: 1-961-921-8950. E-mail: djaalouk@ndu.edu.lb
}

Received: November 17, 2017 Accepted: January 2, 2018 Online Published: January 16, 2018

doi:10.5539/gjhs.v10n2p134

URL: https://doi.org/10.5539/gjhs.v10n2p134

\begin{abstract}
Background: Recent evidence highlighted the potential of habitual smartphone use among youth to become an addiction analogous to established behavioral and substance-related addictions. While investigators revealed independent predictive effects of several sociodemographic factors, personality traits, psychological conditions, and smartphone usage patterns on smartphone addiction (SPA) in university students, none examined the independent effect of age at first smartphone use, a potential predictor variable, on subsequent development of SPA.

Objective: This study aims to examine the independent association between age at first smartphone use and SPA score in a sample of 688 Lebanese undergraduate university students.

Methods: A random sample of 688 undergraduate students selected from Notre Dame University, Lebanon filled out survey forms that included a) questions on socio-demographics, academics, smartphone use, personality type, depression, anxiety, and lifestyle habits; b) 26-item Smartphone Addiction Inventory (SPAI) Scale. Multiple linear regression analyses were used to examine the independent association between age at first use and SPA level.

Results: Mean age at first smartphone use was about 15 years. Younger age at first use of smartphone was found to be significantly associated with several SPA symptoms and correlated with higher total SPAI score. In the unadjusted regression model, higher total SPAI scores were found to be significantly associated with younger age at first smartphone use. This association remained significant in the partially adjusted model, but disappeared in the fully adjusted one when controlling additionally for smartphone use habits.
\end{abstract}

Conclusion: Younger age at smartphone use did not independently predict SPA in this sample of students.

Keywords: smartphone addiction, age at first use, university students

\section{Introduction}

Just recently, a growing body of research has confirmed that perpetual smartphone use among the youth, with particular emphasis on university students, is associated with several addictive symptoms that are analogous to those of substance-use disorder as per the Diagnostic and Statistical Manual of Mental Disorders (DSM-5) including obsession, tolerance, inability to suppress urges, deterioration in life activities, unconcern for adverse effects, and withdrawal (Bian \& Leung, 2015; Kim, Lee, Lee, Nam, \& Chung, 2014; Kwon et al., 2013; Lin et al., 2014). Despite the difficulty of providing an accurate prevalence rate of smartphone addiction amid young people because of methodological variations among research studies, available evidence demonstrated that smartphone addiction rates vary between $11.2 \%$ in African American college students (Bun Lee, 2015), 13.5\% in Chinese university students (Bian \& Leung, 2015), and 17.9\% in Korean adolescents (Mok et al., 2014). In addition, prevalence of high risk to smartphone addiction varied between $30.5 \%$ in Korean university students (Lee, Cho, Kim, \& Noh, 2015), 39.8\% in Turkish university students (Demirci, Akgonul, \& Akpinar, 2015), and 44.6\% in Lebanese private university students (Hawi \& Samaha, 2016).

Published scientific evidence revealed significant independent predictive effects of several sociodemographic factors (age, sex) (Demirci et al., 2015), personality traits and psychological conditions [(extroversion, agreeableness, neuroticism, and conscientiousness) (Bun Lee, 2015), loneliness and shyness (Bian \& Leung, 2015), social interaction anxiety (Bun Lee, 2015), social phobia (Darcin et al., 2016), depression and anxiety (Demirci et al., 2015; Kim et al., 2015), aggression and impulsivity (Kim et al., 2015), and smartphone usage patterns (Bian \& 
Leung, 2015; Zhang, Chen, \& Lee, 2014), on smartphone addiction in university students. It also supported the relationship between younger age of behavior onset during childhood and adolescence and increased likelihood of developing problematic behaviors such as problematic internet use, pathological gambling and problematic mobile phone use during early adulthood. Orsal, Orsal, Unsal, \& Ozalp (2013) found internet addiction median scores to be significantly higher in those who started internet use at an earlier age ( $\leq 9$ vs. 10-12 vs. $\geq 13$ years) in Turkish university students ( $\mathrm{n}=3442$, mean age $=17.6$ years). Slutske et al. (2014) revealed an inverse association between earlier age of initiation of gambling during childhood and adolescence and the likelihood of gambling disorder in adulthood. Sahin, Ozdemir, Unsal, \& Temiz (2013) showed problematic mobile phone use to be statistically significantly associated with younger age at first mobile phone use ( $\leq 13$ vs. $\geq 16$ years) in Turkish university students ( $\mathrm{n}=576$, mean age $=20.8$ years).

Given the well documented independent effect of age at first use on substance dependence and abuse (Bergen-Cico \& Lape, 2013; Liang \& Chikritzhs, 2012; 2013) and the resemblances of behavioral addictions, including mobile phone addiction, to substance-related addictions in many domains including natural history, personality factors, comorbidity, neurobiology, cognitive features, genetic basis, diagnostic criteria, and responsiveness to psychosocial interventions and, to a lesser degree, to pharmacotherapies (Banz, Yip, Yau, \& Potenza, 2016; Brezing, Derevensky, \& Potenza, 2010; Grant, Potenza, Weinstein, \& Gorelick, 2010; Jorgenson, Hsiao, \& Yen, 2016; Karim \& Chaudhri, 2012; Robbins \& Clark, 2015), the odds that early age at first use plays an important role in mobile phone addiction are high. In addition only two studies examined the effect, and not the independent effect, of age at first use of a mobile phone on subsequent development of mobile phone addiction (Darcin et al., 2016; Sahin et al., 2013). This study aims to examine the independent association between age at first use and smartphone addiction score among a sample of Lebanese university students. We hypothesize that younger age at first use is an independent positive predictor of smartphone addiction.

\section{Methods}

\subsection{Participants}

Six hundred eighty eight undergraduate students were recruited from a private university in Lebanon (Notre Dame University). Students were randomly selected from the pool of "Natural Sciences", liberal arts courses (LACs). LACs were targeted because students from all of the different faculties at NDU are required to take at least one course from each of the pools of LACs.

\subsection{Procedure}

Email invitations were sent to the randomly picked students to participate in a web-based survey. Those who responded positively $(92.5 \%)$ were then asked to fill out two survey forms. Collection of data took place during academic year 2014- 2015.

\subsection{Measures}

One survey form included questions on socio-demographics (age, sex, dwelling ( $\mathrm{n}=634$ ), weekly hours of work ), academics (cumulative grade-point-average [GPA], class), psychological health (depression and anxiety, $n=417$ ), smartphone use (age at first use, duration of use on a weekday, reason for use $(n=634)$ ), personality type $(n=634)$, and few lifestyle behaviors (smoking and alcohol drinking, $n=634$ ). With regard to age at first use of smartphone, participants were asked to respond to the following question: At what age did you have your first smartphone and start to use it? Excessive smartphone use was defined by at least 5 hours (median number of hours spent using smartphone) on a weekday. The other form included a 26-item Smartphone Addiction Inventory (SPAI) Scale (Lin et al., 2014), which consists of four subscales: compulsive behavior (CB; 9 items), functional impairment (FI; 8 items), withdrawal (W; 6 items) and tolerance (T; 3 items). The Cronbach's alpha for the SPAI scale was reported to be 0.94 (Lin et al., 2014). Participants were asked to rate items on a 4-point Likert scale, $1=$ "strongly disagree", $2=$ "somewhat disagree"; $3=$ "somewhat agree"; $4=$ "strongly agree" so that the total SPAI score (Addiction Score) ranges from 26 to 104 . These four categories were collapsed into two categories: disagree (strongly disagree + somewhat disagree) and agree (somewhat agree+ strongly agree). The Patient Health Questionnaire-2 (PHQ-2), and the Generalized Anxiety Disorder-2 (GAD-2), each consisting of the two core DSM-IV items for major depressive disorder and generalized anxiety disorder, respectively, were used to screen for depression and anxiety (Kroenke, Spitzer, \& Williams, 2003; Kroenke, Spitzer, Williams, Monahan, \& Löwe, 2007; Kroenke, Spitzer, Williams, \& Löwe, 2010). Each of the total PHQ-2 and GAD-2 score ranges between 0 to 6 with a score of 3 or greater being recommended for use as the cut-point for identifying depressed/ anxious people (www.phqscreeners.com). Statistical tests were performed to ensure that respondents and non-respondents were similar. 


\subsection{Statistical Analyses}

Continuous and categorical variables were summarized as mean \pm standard deviation and $\mathrm{n}(\%)$, respectively. Comparisons of continuous characteristics between two/ more than two unrelated groups were performed using the independent samples T Test (Mann-Whitney-U-test)/ analysis of variance (Kruskal Wallis test), respectively. Categorical variables were compared using the chi square test /Fisher's exact test. Multiple linear regression was used to examine the association between age at first use (main independent variable) and level of smartphone addiction (total SPAI score- dependent variable), after adjusting for confounding. The assumptions of linear regression (normality, linearity, multicollinearity and homoscedasticity) were tested to ensure that none is violated. Independent variables that were found to be significantly associated with smartphone addiction level in the bivariate analyses were entered into the models. Model 1 was unadjusted, showing the effect of the main independent variable on the dependent variable. Model 2 was adjusted for age, personality type, depression and anxiety scores and class. Model 3 was our fully adjusted model in which smartphone-use-related variables were additionally entered into model 2 (duration of smartphone use on a weekday and reasons for smartphone use). In our analyses, missing values were excluded case by case/ pairwise. Data analyses were carried out using SPSS version 22 for Windows. Statistical significance was defined by a p-value of less than 0.05 .

\subsection{Ethical Approval}

The study was approved by the Institutional Review Board at Notre Dame University (NDU), Lebanon. Informed consent was obtained from all study participants prior to enrollment in the study.

\section{Results}

The study sample consisted of 688 undergraduate students. The majority were men (53\%) with a mean age of $20.64 \pm 1.88$ years. Their mean age at first use of smartphone was found to be $15.09 \pm 2.12$ years, with about $49 \%$ being excessive users. About $34 \%$ of the students in our sample were smokers, $63 \%$ were alcohol drinkers, $22 \%$ were depressed, and $27 \%$ were anxious. The most common reason for smartphone use was reported to be texting $(83 \%)$ followed by entertainment/calling family members $(67 \%)$, calling friends $(62 \%)$, study-related purposes $(54 \%)$, reading news $(46 \%)$, and other $(26 \%)$ (Table 1$)$.

Table 1. Characteristics of Study Participants $(n=688)$

\begin{tabular}{|c|c|c|c|}
\hline & {$[$ Mean \pm SD (n)] Or n (\%) } & & {$[$ Mean \pm SD (n)] Or n (\%) } \\
\hline Age & $20.64 \pm 1.88(665)$ & Age at first use of smartphone & $15.09 \pm 2.12(665)$ \\
\hline Class & & Total SPAI Score & $55.37 \pm 15.08(460)$ \\
\hline Sophomore (Year 1) & $268(39.4)$ & \multicolumn{2}{|c|}{ Duration of smartphone use/weekday } \\
\hline Junior (Year 2) & $231(33.9)$ & 0 to less than 1 hour & $14(2.1)$ \\
\hline Senior (Year 3) & $182(26.7)$ & 1 to less than 2 hours & $70(10.3)$ \\
\hline GPA & & 2 to less than 3 hours & $55(8.1)$ \\
\hline$\leq 1.99$ & $46(6.7)$ & 3 to less than 4 hours & $133(19.5)$ \\
\hline $2.00-2.99$ & $461(68.4)$ & 4 to less than 5 hours & $78(11.5)$ \\
\hline$\geq 3.00$ & $168(24.9)$ & $\geq$ to 5 hours & $331(48.6)$ \\
\hline Work hours per week & & \multicolumn{2}{|l|}{ Reason for using smartphone } \\
\hline 0 hours & $196(29)$ & Calling family members $(n=634)$ & $421(67)$ \\
\hline $1-10$ hours & $220(32)$ & Calling friends $(\mathrm{n}=634)$ & $387(62)$ \\
\hline 11-15 hours & $94(14)$ & Texting $(n=634)$ & $519(83)$ \\
\hline$>15$ hours & $171(25)$ & Entertainment $(\mathrm{n}=634)$ & $431(67)$ \\
\hline Residence at present time & & Reading News $(\mathrm{n}=634)$ & $290(46)$ \\
\hline Staying with family & $520(83)$ & Other $(n=634)$ & $164(26)$ \\
\hline Staying at one's apartment & $26(4)$ & Study-related purposes $(n=417)$ & $224(54)$ \\
\hline Staying in dormitory & $52(8)$ & Depressed & $89(21.8)$ \\
\hline Other & $32(5)$ & Anxious & $108(26.5)$ \\
\hline
\end{tabular}




\section{Personality type}

Type A

215 (34.4)

Type B

410 (65.6)

\section{Smoking}

Yes

No 414 (66.3)

Alcohol drinking

Yes

No

Younger age at start of smartphone use was found to be significantly associated with lower GPA $(14.29 \pm 1.98$ $(\mathrm{GPA} \leq 1.99)$ vs. $15.19 \pm 2.13$ (GPA 2-2.99), $\mathrm{p}=0.026)$, excessive smartphone use on a weekday $(14.78 \pm 2.08(\geq 5$ hrs/weekday) vs. $15.38 \pm 2.13(<5 \mathrm{hrs} /$ weekday), $\mathrm{p}=0.000)$, use of smartphone for texting $(15.01 \pm 2.08$ (users) vs. $15.52 \pm 2.39$ (non-users), $\mathrm{p}=0.042$ ), and use of smartphone for other purposes (14.76 \pm 2.18 (users) vs. $15.21 \pm$ 2.12 (non-users), $\mathrm{p}=0.021$ ). Females $(\mathrm{F})$ and smokers $(\mathrm{S})$ seem to have started using a smartphone at a younger age than males (M) and nonsmokers (NS), respectively (F: $14.93 \pm 1.99$ vs. M: $15.24 \pm 2.24, p=0.07 ;$ S: $14.86 \pm 2.32$ vs. NS: $15.20 \pm 2.02, p=0.06$ ) (Table 2).

Table 2. Associations between age at first use of smartphone and participants' characteristics (sociodemographic, lifestyle habits, academic performance, smartphone- related)

\begin{tabular}{|c|c|c|}
\hline & $\begin{array}{l}\text { Age at first Smartphone use } \\
\text { Mean } \pm \text { SD (n) }\end{array}$ & P-value \\
\hline $\operatorname{Sex}(n=674)$ & & 0.066 \\
\hline Males & $15.24 \pm 2.24(346)$ & \\
\hline Females & $14.93 \pm 1.99(309)$ & \\
\hline GPA $(n=674)$ & & 0.026 \\
\hline$\leq 1.99$ & $14.29 \pm 1.98(41)^{*}$ & \\
\hline $2.00-2.99$ & $15.19 \pm 2.13(445)^{*}$ & \\
\hline$\geq 3.00$ & $15.10 \pm 2.10(167)$ & \\
\hline Personality type $(n=625)$ & & 0.266 \\
\hline Type A & $14.95 \pm 2.25(210)$ & \\
\hline Type B & $15.15 \pm 2.07(396)$ & \\
\hline Smoking $(n=624)$ & & 0.061 \\
\hline Yes & $14.86 \pm 2.32(207)$ & \\
\hline No & $15.20 \pm 2.02(400)$ & \\
\hline Alcohol drinking $(\mathrm{n}=629)$ & & 0.215 \\
\hline Yes & $15.00 \pm 2.10(382)$ & \\
\hline No & $15.23 \pm 2.19(228)$ & \\
\hline Duration of smartphone use/weekday $(n=681)$ & & 0.000 \\
\hline$\geq 5 \mathrm{hrs}$ & $14.78 \pm 2.08(326)$ & \\
\hline$<5 \mathrm{hrs}$ & $15.38 \pm 2.13(337)$ & \\
\hline \multicolumn{3}{|l|}{ Reason for using smartphone } \\
\hline Calling family members $(n=634)$ & & 0.724 \\
\hline Yes & $15.07 \pm 2.05(408)$ & \\
\hline
\end{tabular}




\begin{tabular}{|c|c|c|}
\hline No & $15.14 \pm 2.32(202)$ & \\
\hline Calling friends $(\mathrm{n}=634)$ & & 0.562 \\
\hline Yes & $15.05 \pm 2.07(373)$ & \\
\hline No & $15.16 \pm 2.25(237)$ & \\
\hline Texting $(n=634)$ & & 0.042 \\
\hline Yes & $15.01 \pm 2.08(506)$ & \\
\hline No & $15.52 \pm 2.39(104)$ & \\
\hline Entertainment $(\mathrm{n}=634)$ & & 0.694 \\
\hline Yes & $15.07 \pm 2.14(422)$ & \\
\hline No & $15.15 \pm 2.15(188)$ & \\
\hline Reading News $(\mathrm{n}=634)$ & & 0.691 \\
\hline Yes & $15.13 \pm 2.19(284)$ & \\
\hline No & $15.06 \pm 2.10(326)$ & \\
\hline Other $(\mathrm{n}=634)$ & & 0.021 \\
\hline Yes & $14.76 \pm 2.18(159)$ & \\
\hline No & $15.21 \pm 2.12(451)$ & \\
\hline Study-related purposes $(n=417)$ & & 0.773 \\
\hline Yes & $14.97 \pm 2.13(220)$ & \\
\hline No & $14.91 \pm 1.90(181)$ & \\
\hline Depression & & 0.499 \\
\hline Yes & $15.06 \pm 2.11(84)$ & \\
\hline No & $14.89 \pm 1.99(309)$ & \\
\hline Anxiety & & 0.245 \\
\hline Yes & $15.13 \pm 2.11(105)$ & \\
\hline No & $14.87 \pm 1.94(287)$ & \\
\hline
\end{tabular}

* $\mathrm{p}$ value pertains to difference between the 2 indicated groups.

In addition, younger age at first use of smartphone was found to be significantly associated with several smartphone addiction symptoms. For instance, the mean age at start of smartphone use of those who reported to use smartphone for a longer period of time and spend more money than they had intended, have slept less than four hours due to using smartphone more than once, feel uneasy once they stop smartphone use for a certain period of time, and be told more than once that they spent too much time on smartphone was found to be significantly lower than those who did not report such symptoms $(14.80 \pm 2.21$ vs. $15.25 \pm 2.08, \mathrm{p}=0.011 ; 14.83 \pm 2.01$ vs. $15.25 \pm 2.15$, $\mathrm{p}=0.015 ; 14.73 \pm 2.17$ vs. $15.26 \pm 2.08, \mathrm{p}=0.003 ; 14.91 \pm 1.98$ vs. $15.31 \pm 2.23, \mathrm{p}=0.016$, respectively) (Table 3 ). In addition, younger age at first use of smartphone showed statistically significant correlation with higher total SPAI score $(\rho=-0.168, p=0.000)$, and with higher scores on each single SPAI subscale: compulsive behavior score $(\rho=-0.144, p=0.001)$, functional impairment $(\rho=-0.095, p=0.027)$, withdrawal score $(\rho=-0.161, p=0.000)$, and tolerance score $(\rho=-0.154, p=0.000)$ (data not shown). 
Table 3. Associations between age at first use of Smartphone and Smartphone Addiction (SPAI) symptoms

\begin{tabular}{|c|c|c|c|}
\hline \multirow{3}{*}{ SPAI Symptoms } & \multicolumn{2}{|c|}{ Age at first use of Smartphone } & \multirow{3}{*}{ P-value } \\
\hline & \multicolumn{2}{|c|}{$\operatorname{Mean} \pm$ SD (n) } & \\
\hline & Agree & Disagree & \\
\hline \multicolumn{4}{|l|}{ Compulsive Behavior } \\
\hline $\begin{array}{l}\text { I feel very vigorous upon smartphone use regardless of the } \\
\text { fatigues experienced }\end{array}$ & $14.85 \pm 2.04(256)$ & $15.24 \pm 2.16(389)$ & 0.025 \\
\hline $\begin{array}{l}\text { I use smartphone for a longer period of time and spend more } \\
\text { money than I had intended }\end{array}$ & $14.80 \pm 2.21(230)$ & $15.25 \pm 2.08(413)$ & 0.011 \\
\hline $\begin{array}{l}\text { Although using smartphone has brought negative effects on } \\
\text { my interpersonal relationships, the amount of time spent on } \\
\text { Internet remains unreduced }\end{array}$ & $14.90 \pm 2.01(245)$ & $15.21 \pm 2.19(402)$ & 0.070 \\
\hline $\begin{array}{l}\text { I feel distressed or down once I cease using smartphone for a } \\
\text { certain period of time }\end{array}$ & $14.93 \pm 2.18(192)$ & $15.18 \pm 2.08(451)$ & 0.182 \\
\hline I fail to control the impulse to use smartphone & $14.98 \pm 1.98(226)$ & $15.17 \pm 2.19(411)$ & 0.279 \\
\hline My recreational activities are reduced due to smartphone use & $14.99 \pm 2.12(169)$ & $15.15 \pm 2.14(446)$ & 0.428 \\
\hline My life would be joyless hadn't there been smartphone & $14.84 \pm 2.06(183)$ & $15.23 \pm 2.15(428)$ & 0.037 \\
\hline $\begin{array}{l}\text { Surfing the smartphone has exercised negative effects on my } \\
\text { physical health. For example, viewing smartphone when } \\
\text { crossing the street; fumbling with one's smartphone while } \\
\text { driving or waiting, and resulted in danger }\end{array}$ & $15.05 \pm 2.04(233)$ & $15.15 \pm 2.20(370)$ & 0.556 \\
\hline $\begin{array}{l}\text { I try to spend less time on smartphone, but the efforts were } \\
\text { in vain }\end{array}$ & $14.97 \pm 2.18(206)$ & $15.18 \pm 2.10(403)$ & 0.255 \\
\hline \multicolumn{4}{|l|}{ Functional impairment } \\
\hline $\begin{array}{l}\text { I have slept less than four hours due to using smartphone } \\
\text { more than once }\end{array}$ & $14.83 \pm 2.01(235)$ & $15.25 \pm 2.15(418)$ & 0.015 \\
\hline $\begin{array}{l}\text { I find myself indulged on the smartphone at the cost of } \\
\text { hanging out with friends }\end{array}$ & $15.07 \pm 2.31(132)$ & $15.11 \pm 2.07(496)$ & 0.856 \\
\hline $\begin{array}{l}\text { I feel aches and soreness in the back or eye discomforts due } \\
\text { to excessive smartphone use }\end{array}$ & $15.18 \pm 2.06(274)$ & $15.06 \pm 2.17(360)$ & 0.475 \\
\hline $\begin{array}{l}\text { To use smartphone has exercised certain negative effects on } \\
\text { my schoolwork or job performance }\end{array}$ & $15.19 \pm 2.00(222)$ & $15.04 \pm 2.19(405)$ & 0.408 \\
\hline $\begin{array}{l}\text { My interaction with family members is decreased on account } \\
\text { of smartphone use }\end{array}$ & $15.03 \pm 1.91(251)$ & $15.16 \pm 2.26(366)$ & 0.457 \\
\hline $\begin{array}{l}\text { I make it a habit to use smartphone and the sleep quality and } \\
\text { total sleep time decreased }\end{array}$ & $15.00 \pm 2.14(229)$ & $15.17 \pm 2.16(369)$ & 0.322 \\
\hline $\begin{array}{l}\text { I need to spend an increasing amount of time on smartphone } \\
\text { to achieve same satisfaction as before }\end{array}$ & $14.87 \pm 2.22(169)$ & $15.18 \pm 2.10(439)$ & 0.115 \\
\hline I feel tired on daytime due to late-night use of smartphone & $15.03 \pm 2.05(215)$ & $15.13 \pm 2.18(390)$ & 0.588 \\
\hline \multicolumn{4}{|l|}{ Withdrawal } \\
\hline $\begin{array}{l}\text { I feel uneasy once I stop smartphone for a certain period of } \\
\text { time }\end{array}$ & $14.73 \pm 2.17(211)$ & $15.26 \pm 2.08(442)$ & 0.003 \\
\hline $\begin{array}{l}\text { I feel restless and irritable when the smartphone is } \\
\text { unavailable }\end{array}$ & $14.78 \pm 2.13(261)$ & $15.28 \pm 2.11(394)$ & 0.003 \\
\hline $\begin{array}{l}\text { The idea of using smartphone comes as the first thought on } \\
\text { mind when waking up each morning }\end{array}$ & $14.90 \pm 1.96(402)$ & $15.42 \pm 2.34(227)$ & 0.005 \\
\hline $\begin{array}{l}\text { I feel missing something after stopping smartphone for a } \\
\text { certain period of time }\end{array}$ & $14.82 \pm 2.09(285)$ & $15.34 \pm 2.13(336)$ & 0.002 \\
\hline
\end{tabular}




\begin{tabular}{|c|c|c|c|}
\hline $\begin{array}{l}\text { I feel the urge to use my smartphone again right after I } \\
\text { stopped using it }\end{array}$ & $14.95 \pm 1.98(261)$ & $15.23 \pm 2.24(348)$ & 0.101 \\
\hline I cannot have meal without smartphone use & $15.05 \pm 2.18(116)$ & $15.11 \pm 2.13(491)$ & 0.781 \\
\hline \multicolumn{4}{|l|}{ Tolerance } \\
\hline $\begin{array}{l}\text { I was told more than once that I spent too much time on } \\
\text { Smartphone }\end{array}$ & $14.91 \pm 1.98(358)$ & $15.31 \pm 2.23(299)$ & 0.016 \\
\hline $\begin{array}{l}\text { I find that I have been hooking on smartphone longer and } \\
\text { longer }\end{array}$ & $14.73 \pm 2.15(322)$ & $15.42 \pm 2.04(328)$ & 0.000 \\
\hline $\begin{array}{l}\text { I have increased substantial amount of time using } \\
\text { smartphone per week in recent } 3 \text { months }\end{array}$ & $14.93 \pm 2.08(262)$ & $15.23 \pm 2.15(379)$ & 0.076 \\
\hline
\end{tabular}

Multiple linear regression analysis was used to examine the ability of age at first use of smartphone to predict level of smartphone addiction (total SPAI score), after adjusting for confounding effects. In Model 1, higher addiction levels were found to be significantly associated with younger age at first use of smartphone, by which the total SPAI score increases by about 1.2 units for a 1 - year decrease in age at first use of smartphone, and with age at first use of smartphone explaining about $3 \%$ of the variance in total SPAI scores. The association between age at first use of smartphone and addiction level remained significant after adjusting for the effects of independent variables representing personal characteristics (age, personality type, depression score, anxiety score and class) in Model 2, whereby the total SPAI score increases by about 1 unit for a 1 -year decrease in age at first use of smartphone, and with all the independent variables explaining about $12 \%$ of the variance in total SPAI scores. When the independent variables pertaining to smartphone use habits (duration/ hours of smartphone use, and use of smartphone for calling family members, entertainment and other purposes) were entered into model 2 (Model 3), the variance in total SPAI scores explained by all the independent variables almost doubled (23\%), and the observed significant association between age at first use of smartphone and addiction score in the previous models disappeared. In the final model (Model 3), higher total SPAI score was found to be significantly associated with personality type A, higher depression score, excessive smartphone use ( $\geq 5$ hours/ weekday), non-use of smartphone for calling family members, and use of smartphone for entertainment purposes with excessive smartphone use having the largest beta coefficient $(\beta=0.263, p=0.000)$ followed by depression score $(\beta=0.185$, $p=0.003)$, non-use of smartphone to call family members $(\beta=-0.147, p=0.015)$, personality type $A(\beta=0.124$, $\mathrm{p}=0.028)$ and use of smartphone for entertainment purposes $(\beta=0.122, \mathrm{p}=0.043)($ Table 4$)$.

Table 4. Association between Total SPAI Score and Age at First Use, as Assessed by Multiple Linear Regression *

\begin{tabular}{|c|c|c|c|c|c|c|c|}
\hline & \multirow{2}{*}{$\begin{array}{l}\text { Unstandardized } \\
\beta\end{array}$} & \multirow[b]{2}{*}{ S.E. } & \multirow{2}{*}{$\begin{array}{l}\text { Standardized } \\
\beta\end{array}$} & \multirow[b]{2}{*}{ p-value } & \multicolumn{2}{|c|}{$95 \%$ CI } & \multirow{2}{*}{$\begin{array}{l}\mathbf{R} \\
\text { square }\end{array}$} \\
\hline & & & & & $\begin{array}{l}\text { Lower } \\
\text { Boundary }\end{array}$ & $\begin{array}{l}\text { Upper } \\
\text { Boundary }\end{array}$ & \\
\hline Model 1 & & & & & & & 0.028 \\
\hline Age at First Use & -1.182 & 0.330 & -0.166 & 0.000 & -1.839 & -0.534 & \\
\hline Model 2 & & & & & & & 0.119 \\
\hline Age at First Use & -1.006 & 0.466 & -0.142 & 0.032 & -1.923 & -0.088 & \\
\hline Age & -0.796 & 0.592 & -0.099 & 0.180 & -1.961 & 0.370 & \\
\hline Personality type & 4.176 & 1.883 & 0.132 & 0.027 & 0.468 & 7.883 & \\
\hline Depression Score & 2.522 & 0.793 & 0.210 & 0.002 & 0.961 & 4.083 & \\
\hline Anxiety Score & 0.480 & 0.726 & 0.044 & 0.509 & -0.949 & 1.910 & \\
\hline Class & 1.361 & 1.307 & 0.073 & 0.299 & -1.212 & 3.934 & \\
\hline Model 3 & & & & & & & 0.230 \\
\hline Age at First Use & -0.581 & 0.446 & -0.082 & 0.194 & -1.460 & 0.298 & \\
\hline Age & -0.938 & 0.565 & -0.117 & 0.098 & -2.050 & 0.173 & \\
\hline Personality type & 3.925 & 1.775 & 0.124 & 0.028 & 0.429 & 7.421 & \\
\hline
\end{tabular}




\begin{tabular}{|c|c|c|c|c|c|c|}
\hline Depression Score & 2.217 & 0.749 & 0.185 & 0.003 & 0.741 & 3.692 \\
\hline Anxiety Score & 0.395 & 0.689 & 0.037 & 0.566 & -0.961 & 1.752 \\
\hline Class & 1.039 & 1.234 & 0.055 & 0.401 & -1.390 & 3.468 \\
\hline $\begin{array}{l}\text { Duration of smartphone } \\
\text { use/weekday }\end{array}$ & 7.915 & 1.690 & 0.263 & 0.000 & 4.588 & 11.243 \\
\hline $\begin{array}{l}\text { Use of smartphone to call } \\
\text { family members }\end{array}$ & -4.702 & 1.929 & -0.147 & 0.015 & -8.501 & -0.904 \\
\hline $\begin{array}{l}\text { Use of smartphone for } \\
\text { entertainment purposes }\end{array}$ & 3.974 & 1.951 & 0.122 & 0.043 & 0.133 & 7.815 \\
\hline $\begin{array}{l}\text { Use of smartphone for } \\
\text { other reasons }\end{array}$ & 3.174 & 1.954 & 0.093 & 0.106 & -0.674 & 7.022 \\
\hline
\end{tabular}

* Dependent Variable: Total SPAI Score

\section{Discussion}

In summary, mean age at first use of smartphone in our sample was about 15 years, and close to $50 \%$ use their smartphones for 5 or more hours during a weekday mostly for texting, entertainment and calling family members. Those who reported younger age at first smartphone use were more likely to have below good academic standing, to use their smartphones excessively during a weekday for texting and other purposes, to have several smartphonerelated addictive symptoms (excitement despite fatigue, difficulty to control device use, gratification, sleep deprivation, tolerance and withdrawal), and to have higher smartphone addiction score. Nonetheless, younger age at first smartphone use did not associate with personality type, current smoking or alcohol drinking. In the unadjusted multiple linear regression model, age at first smartphone use emerged as a significant negative predictor of smartphone addiction level. Although its predictive negative effect remained statistically significant after controlling for age, personality type, depression and anxiety scores, and class; the independent predictive negative effect of age at first smartphone use disappeared when time spent using smartphone per weekday and purpose of using smartphone were further controlled for.

Our findings from correlation analysis of a significant positive association between younger age at first use and development of smartphone addiction are comparable to those of Orsal et al. (2013) and Sahin et al. (2013) which revealed significant associations between younger age at first use of internet ( $\leq 9$ vs. 10-12 vs. $\geq 13$ years) and higher internet addiction median score, and between younger age at first mobile phone use ( $\leq 13$ vs. $\geq 16$ years $)$ and higher mobile phone addiction median score in Turkish university students, respectively. However, they were unlike those of Darcin et al. (2016) who did not find any significant correlation between earlier age at first smartphone use and smartphone addiction among a sample of Turkish university students. Yet, regression analysis revealed the influence of several factors on smartphone addiction which when we controlled for, the significant positive association between younger age at first use and smartphone addiction score was no more evident.

The attenuating effects of depression score and personality type A on the negative predictive effect of age at first use on smartphone addiction score were expected. The former expectation is in view of prior evidence of an independent positive predictive effect of depression on smartphone addiction in Turkish (Demirci et al., 2015) and Korean (Kim et al., 2015) university students. In addition, Brezing et al. (2010) in their review of behavioral addictions in youth alluded to the positive association between depression and problematic internet use in adolescents and college students, where internet use is used as a coping strategy. Likewise, we had similar expectation with regard to the effect of personality type A; once more presumed by findings from earlier studies revealing significant positive association between neurotic personality trait and smartphone addiction in Korean college students (Mok et al., 2014), personality type A and problematic mobile phone use in Turkish university students (Sahin et al., 2013), and type A behavior traits and mobile phone dependence after adjustment for health-related lifestyle habits and depressive state in Japanese medical university students (Masahiro \& Satoko, 2013).

Excessive use of smartphone (defined as 5 or more hours during a weekday) emerged as the most powerful independent positive predictor of smartphone addiction controlling for age at first smartphone use, age, personality type, depression and anxiety scores, class, and purpose of using smartphone. This is in agreement with prior reports of a significant positive association between amount of time spent daily using smartphones $(>16 \mathrm{vs}$. $<4$ hours) and smartphone addiction score in Turkish medical students (Demirci et al., 2014), and amount of time spent using the Internet per day and smartphone addiction score in Korean college students (Kim et al., 2015). 
Comparatively, internet addiction scores increased significantly with increased number of hours spent on the internet per day, in a dose-dependent manner $(\leq 3,4-6,7-12$, and $\geq 13$ hours spent daily), among Turkish University students (Orsal et al., 2013), and duration of internet usage emerged as a significant independent positive predictor of internet addiction controlling for sociodemographic factors, dysfunctional attitude, self-esteem, personality traits, psychiatric treatment history and depression in a sample of Turkish medical university students (Şenormanc1 et al., 2014). Also, problematic mobile phone use median score was significantly higher among excessive users of daily mobile phone use ( $\geq 5$ vs. $<5$ hours) in Turkish university students (Sahin et al., 2013), and time spent on social networking applications emerged as a significant predictor of mobile phone addiction in a sample of university students from the US (Salehan \& Negahban, 2013). Noteworthy, findings from a study among a sample of 13,284 school adolescents (mean age $=15.8$, age range $=14-17$ years) from seven European countries revealed that age at first use of the internet had a less independent predictive effect on dysfunctional internet behavior compared to time spent on social networking sites or online games, with the latter emerging as a significant positive predictor of dysfunctional internet behavior, after controlling for age, gender, parental educational level, country, time spent on social networking sites, and average hours of playing games online per weekday (Tsitsika et al., 2014).

Furthermore, while several studies reported on the relationship between smartphone usage and addiction among university students (Bian \& Leung, 2015; Darcin et al., 2016; Salehan \& Negahban, 2013; Zhang et al., 2014), comparison of findings is not possible in view of the different descriptions/ classifications of the construct "smartphone usage" and the array of confounding variables they controlled for. In our sample, use of smartphone to call family members had an independent protective effect on smartphone addiction, pursuant to the finding of a direct positive predictive effect of family stress on smartphone addiction reported in a convenient sample of Taiwanese university students (Chiu, 2014). In contrast, use of smartphone for entertainment had a significant positive predictive adverse effect on smartphone addiction, comparable to the findings of Demirci et al. (2014) of higher mean smartphone addiction score in Turkish medical students who used smartphone for gaming than those who used it for calling, text messaging, or other purposes. Also, in a convenient sample of Chinese university students, perceived enjoyment had a significant effect on smartphone addiction unlike information seeking and interpersonal communication (Zhang et al., 2014).

\subsection{Study Strengths and Limitations}

To our knowledge, our study is the first one to employ a holistic assessment of the effect of younger age at first use of smartphone on later development of smartphone addiction in university undergraduate students, controlling for multiple sociodemographic, academic, lifestyle, personality and mental health, and smartphone-related parameters. Though earlier age at first use showed positive association with smartphone addiction; however, its effect was lost when controlling for smartphone-related variables in particular, a measure that was missed by many, if not all, researchers who looked at the association between younger age of onset of behavior and smartphone addiction. In addition, the tools that we used to assess smartphone addiction level and screen for depression and anxiety were validated and have been used among samples of university students.

On the other hand, our study bears several limitations. First, we adopted a cross-sectional design so it is not possible to make the causal inference that an independent variable caused the observed changes in the dependent variable (smartphone addiction score). Second, data on many of the independent variables in our study were self-reported and may possibly be inaccurate such as when asked about age at first smartphone use, time spent and reason for using smartphone during a weekday. Third, other factors known to associate with younger age at first use and the development of smartphone addiction were not controlled for, such as particular individual personality characteristics like impulsivity (Dalbudak \& Evren, 2014; Kim et al., 2015), disruptive behavior problem (Dalbudak \& Evren, 2014; Slutske et al., 2014), and family environment (Slutske et al., 2014).

\section{Conclusion and Future Implications}

In conclusion, younger age at use of smartphone did not predict smartphone addiction in university undergraduate students after controlling for multiple factors. Yet in view of the multifactorial nature of behavioral addictions, it is crucial that parents monitor and promote controlled and responsible use of smartphones among their youngsters, improve communication and seek help for vulnerable ones so that to reduce development of smartphone addiction. Future studies shall aim at identifying factors which underlie excessive use of smartphone; hence addressing those factors in interventions directed at individuals vulnerable to smartphone addiction. Moreover, longitudinal studies examining the sequential relationship between multiple factors that were found to influence smartphone addiction are needed.

\section{Competing Interests Statement}

The authors declare that they have no competing or potential conflicts of interest. 


\section{References}

Banz, B., Yip, S., Yau, Y., \& Potenza, M. (2016). Chapter 16- Behavioral addictions in addiction medicine: from mechanisms to practical considerations. In Progress in Brain Research, 223, 311-328. https://doi.org/10.1016/bs.pbr.2015.08.003

Bergen-Cico, D., \& Lape, M. (2013). Age of first use as a predictor of current alcohol and marijuana use among college-bound emerging adults. Journal of Child \& Adolescent Substance Abuse, 22, 235-253. https://doi.org/10.1080/1067828X.2012.733591

Bian, M., \& Leung, L. (2015). Linking loneliness, shyness, smartphone addiction symtpoms, and patterns of smartphone use to social capital. Social Science Computer Review, 33(1), 61-79. https://doi.org/10.1177/0894439314528779

Brezing, C., Derevensky, J., \& Potenza, M. (2010). Non-substance Addictive Behaviors in Youth: Pathological Gambling and Problematic Internet Use. Child and Adolescent Psychiatric Clinics of North America, 19(3), 625-641. https://doi.org/10.1016/j.chc.2010.03.012

Bun Lee, E. (2015). Too much information: heavy smartphone and Facebook utilization by African American young adults. Journal of Black Studies, 46(1), 44-61. https://doi.org/10.1177/0021934714557034

Chiu, S. (2014). The relationship between life stress and smartphone addiction on Taiwanese university students: A mediation model of learning self-efficacy and social self-efficay. Computers in Human Behavior, 34, 49-57. https://doi.org/10.1016/j.chb.2014.01.024

Dalbudak, E., \& Evren, C. (2014). The relationship of Internet addiction severity with attention deficit hyperactivity disorder symptoms in Turkish university students; impact of personality traits, depression and anxiety. Comprehensive Psychiatry, 55(3), 497-503. https://doi.org/10.1016/j.comppsych.2013.11.018

Darcin, A., Kose, S., Noyan, C., Nurmedov, S., Yılmaz, O., \& Dilbaz, N. (2016). Smartphone addiction and its relationship with social anxiety and loneliness. Behavior \& Information Technology, 35(7), 520-525. https://doi.org/10.1080/0144929X.2016.1158319

Demirci, K., Akgonul, M., \& Akpinar, A. (2015). Relationship of smartphone use severity with sleep quality, depression, and anxiety in university students. Journal of Behavioral Addictions, 4(2), 85-92. https://doi.org/10.1556/2006.4.2015.010

Demirci, K., Orhan, O., Demirdas, A., Akpınar, A., \& Sert, H. (2014). Validity and reliability of the Turkish version of the smartphone addiction scale in a younger population. Bulletin of Clinical Psychopharmacology, 24(3), 226-234. https://doi.org/10.5455/bcp.20140710040824

Grant, J., Potenza, M., Weinstein, A., \& Gorelick, D. (2010). Introduction to Behavioral Addictions. The American Journal of Drug and Alcohol Abuse, 36, 233-241. https://doi.org/10.3109/00952990.2010.491884

Hawi, N., \& Samaha, M. (2016). To excel or not to excel: Strong evidence on the adverse effect of smartphone addiction on academic performance. Computers \& Education, 98, 81-89. https://doi.org/10.1016/j.compedu.2016.03.007

http://www.phqscreeners.com. Instruction Manual- Instructions for Patient Health Questionnaire (PHQ) and GAD-7 Measures. August 31, Retrieved 2016, from https://phqscreeners.pfizer.edrupalgardens.com/sites/g/files/g10016261/f/201412/instructions.pdf

Jorgenson, A., Hsiao, R., \& Yen, C. (2016). Internet addiction and other behavioral addictions. Child \& Adolescent Psychiatric Clinics of North America, 25, 509-520. https://doi.org/10.1016/j.chc.2016.03.004

Karim, R., \& Chaudhri, P. (2012). Behavioral addictions: an overview. Journal of Psychoactive Drugs, 44, 5-17. https://doi.org/10.1080/02791072.2012.662859

Kim, D., Lee, Y., Lee, J., Nam, J., \& Chung, Y. (2014). Development of Korean Smartphone addiction proneness scale for youth. PLoS One, 9(5), e97920. https://doi.org/10.1371/journal.pone.0097920

Kim, M., Kim, H., Kim, K., Ju, S., Choi, J., \& Yu, M. (2015). Smartphone Addiction: (Focused Depression, Aggression and Impulsion) among College Students. Indian Journal of Science \& Technology, 8(25). https://doi.org/10.17485/ijst/2015/v8i25/80215

Kroenke, K., Spitzer, R., \& Williams, J. (2003). The Patient Health Questionnaire-2: validity of a two-item depression screener. Medical Care, 41(11), 1284-1292.

Kroenke, K., Spitzer, R., Williams, J., \& Löwe, B. (2010). The Patient Health Questionnaire somatic, anxiety, and depressive symptom scales: a systematic review. General Hospital Psychiatry, 32(4), 345-359. 
https://doi.org/10.1016/j.genhosppsych.2010.03.006

Kroenke, K., Spitzer, R., Williams, J., Monahan, P., \& Löwe, B. (2007). Anxiety disorders in primary care: prevalence, impairment, comorbidity, and detection. Annals of Internal Medicine, 146(5), 317-325.

Kwon, M., Lee, J. Y., Won, W. Y., Park, J. W., Min, J. A., Hahn, C., ... Kim, D. J. (2013). Development and validation of a smartphone addiction scale (SAS). PLoS One, 8(2), e56936. https://doi.org/10.1371/journal.pone.0056936

Lee, J., Cho, B., Kim, Y., \& Noh, J. (2015). Smartphone addiction in university students and its implication for learning. In G. Chen, V. Kumar, H. R. Kinshuk, \& S. Kong (Eds.), Emerging Issues in Smart Learning. Springer-Verlag. https://doi.org/10.1007/978-3-662-44188-6_40

Liang, W., \& Chikritzhs, T. (2012). The association between age at first use of alcohol and alcohol consumption levels among adult general drinking population. Journal of Public Health, 20, 615-620. https://doi.org/10.1007/s10389-012-0502-2

Liang, W., \& Chikritzhs, T. (2013). Age at first use of alcohol and risk of heavy alcohol use: A population-based study. BioMed Research International, vol. 2013, Article ID 721761. https://doi.org/10.1155/2013/721761

Lin, Y., Chang, L., Lee, Y., Tseng, H., Kuo, T., \& Chen, S. (2014). Development and validation of the Smartphone Addiction Inventory (SPAI). PLoS One, 9(6), e98312. https://doi.org/10.1371/journal.pone.0098312

Masahiro, T., \& Satoko, E. (2013). Multifactorial study of mobile phone dependence in medical students: relationship to health-related lifestyle, type A behavior, and depressive state. Open Journal of Preventive Medicine, 3(1), 99-103. https://doi.org/10.4236/ojpm.2013.31012

Mok, J. Y., Choi, SW., Kim, D. J., Choi, J. S., Lee, J., Ahn, H., Choi, E. J., \& Song, W. Y. (2014). Latent class analysis on internet and smartphone addiction in college students. Neuropsychiatric Disease and Treatment, 10, 817-828. https://doi.org/10.2147/NDT.S59293

Orsal, O., Orsal, O., Unsal, A., \& Ozalp, S. (2013). Evaluation of Internet Addiction and Depression Among University Students. Procedia - Social and Behavioral Sciences, 82, 445-454. https://doi.org/10.1016/j.sbspro.2013.06.291

Robbins, T., \& Clark, L. (2015). Behavioral addictions. Current Opinion in Neurobiology, 30, 66-72. https://doi.org/10.1016/j.conb.2014.09.005

Sahin, S., Ozdemir, K., Unsal, A., \& Temiz, N. (2013). Evaluation of mobile phone addiction level and sleep quality in university students. Pakistan Journal of Medical Sciences, 29(4), 913-918. https://doi.org/10.12669/pjms.294.3686

Salehan, M., \& Negahban, A. (2013). Social networking on smartphones: When mobile phones become addictive. Computers in Human Behavior, 29, 2632-2639. https://doi.org/10.1016/j.chb.2013.07.003

Şenormanc1, O., Saraçlı, O., Atasoy, N., Şenormanc1, G., Koktürk, F., \& Atik, L. (2014). Relationship of Internet addiction with cognitive style, personality, and depression in university students. Comprehensive Psychiatry, 55(6), 1385-1390. https://doi.org/10.1016/j.comppsych.2014.04.025

Slutske, W., Deutsch, A., Richmond-Rakerd, L., Chernyavskiy, P., Statham, D., \& Martin, N. (2014). Test of a potential causal influence of earlier age of gambling initiation on gambling involvement and disorder: a multi-level discordant twin design. Psychology of Addictive Behaviors, 28(4), 1177-1189. https://doi.org/10.1037/a0035356

Tsitsika, A., Janikian, M., Schoenmakers, T., Tzavela, E., Olafsson, K., Wojcik, S., \& Richardson, C. (2014). Internet addictive behavior in adolescence: a cross-sectional study in seven European countries. Cyberpsychology, Behavior, and Social Networking, 17(8), 528-535. https://doi.org/10.1089/cyber.2013.0382

Zhang, K., Chen, C., \& Lee, M. (2014). Understanding the role of motives in smartphone addiction. PACIS 2014 Proceedings. Retrieved March 13, 2015, from http://aisel.aisnet.org/pacis2014/131

\section{Copyrights}

Copyright for this article is retained by the author(s), with first publication rights granted to the journal.

This is an open-access article distributed under the terms and conditions of the Creative Commons Attribution license (http://creativecommons.org/licenses/by/4.0/). 